УДК 378.147

\title{
Н.Е. Брим
}

\section{УЧЕБНОЕ ВЗАИМОДЕЙСТВИЕ В РАМКАХ ДИСТАНЦИОННОГО ОБУЧЕНИЯ (НА ПРИМЕРЕ СТУДЕНТОВ-ЛИНГВИСТОВ)}

\begin{abstract}
В статье рассматривается проблема организации учебного взаимодействия в рамках дистанционного обучения, базирующегося на положениях синергетического и личностно ориентированного подхода к учебному взаимодействию преподавателя и обучающихся как самоорганизующейся и взаимообогащающейся системе. Эффективность такого взаимодействия достигается выявлением и обоснованием соответствующих педагогических условий: педагогического содействия и технического сопровождения, реализующихся в структурных компонентах программы дистанционного обучения. Автором описываются модели дистанционного учебного взаимодействия и алгоритм действий его участников, обращается внимание на выбор оптимальных образовательных ресурсов: методов, форм и средств дистанционного обучения. В статье представлены и проанализированы результаты опроса преподавателей Удмуртского государственного университета и студентов-лингвистов, изучающих иностранный язык, о проблеме дистанционного обучения, приводятся некоторые факты из личного опыта работы в этом направлении. В заключение даются методические рекомендации по организации дистанционного учебного взаимодействия.
\end{abstract}

Ключевые слова: учебное взаимодействие, информационно-коммуникационные технологии, электроннообразовательная среда, дистанционное обучение, программа.

DOI: $10.35634 / 2412-9550-2020-30-3-313-322$

\section{1. Введение}

При демократизации и гуманизации современного образования поднимается вопрос о грамотной организации учебного взаимодействия, стремящегося к достижению гармоничного единства общественного и личного, большого и малого, к глубокому пониманию и оценке поставленных целей и задач, результатов, к уважению других и самого себя.

Модернизация, оптимизация и перестройка учебного процесса в сегодняшнее время предполагают также развитие электронной информационно-образовательной среды. На официальных сайтах многих учебных заведений предлагается подборка технологий, инструментов и практик дистанционного обучения, организуются вебинары и видео-лекции для сотрудников и студентов, позволяющие минимизировать стресс вхождения в новый формат учебного взаимодействия, анализируются преимущества и недостатки дистанционных образовательных площадок. Происходят изменения в рабочих программах и фондах оценочных средств, меняются требования, предъявляемые как к преподавателю, так и обучающимся.

В формах предъявления выполненного задания, например, называются следующие пункты:

- при устном ответе на экзаменационные задания (вопросы), в том числе при собеседовании, применяется система видео-конференц-связи, обеспечивающая двустороннюю видео- и аудиосвязь в режиме реального времени через информационно-телекоммуникационную сеть Интернет;

- при выполнении обучающимся письменной работы (реферата, эссе, контрольной работы, практического задания и др.) осуществляется ее отправка преподавателю в электронном виде по электронной почте.

Указываются новые требования к техническому оснащению учебного взаимодействия и процедуры оценивания:

- наличие персонального компьютера/ноутбука со стабильным интернет-соединением; процесcop Intel или AMD от 2 ГГц. 2 Гб оперативной памяти (RAM) и 120 МБ свободного места на жестком диске; операционная система Windows 7/8/8.1/10; сетевое подключение со скоростью более 512 Кбит/с в обоих направлениях;

- наличие видеокамеры (веб-камера) с разрешением не менее 2 Мр широкой зоны охвата, позволяющей продемонстрировать помещение, в котором находится обучающийся, материалы, которыми он пользуется, и обеспечивающей непрерывную трансляцию процедуры промежуточной аттестации; видеокарта от 64 МБ оперативной памяти (VRAM) и др. 
Таким образом, актуальность данной статьи обусловливается прежде всего тем, что все участники дистанционного учебного взаимодействия должны владеть информационно-коммуникативными технологиями, быть уверенными компьютерными пользователями. В то же время, при все более нарастающей потребности в использовании электронных образовательных ресурсов и специально разработанных курсов, можно говорить о неопределенности этапов перехода к дистанционному обучению и недостаточной разработанности данного направления в педагогической науке. Это противоречие обусловливает проблему исследования: каковы педагогические условия, при которых дистанционное учебное взаимодействие будет эффективным, а образовательная среда - комфортной и благоприятной? Целью работы является разработка и содержательное наполнение программы учебного взаимодействия в рамках дистанционного обучения на примере студентов-лингвистов.

\section{2. Основная часть}

\section{Теоретические исследования учебного взаимодействия}

Центральным понятием статьи является «учебное взаимодействие». Учебное взаимодействие рассматривается в педагогике как сложный процесс, состоящий из дидактических, воспитательных, социальных компонентов $[1 ; 10 ; 11]$.

Структурные элементы учебного взаимодействия были представлены нами ранее в диссертационном исследовании: создание образовательной ситуации (отрывок учебного процесса, направленный на совместное решение поставленной задачи преподавателем и обучающимися), педагогическая пресуппозиция (предвосхищение успеха обучающихся, вера в их возможности), культура оценивания ошибок (латентное руководство мыслительной деятельностью обучающихся), педагогическое содействие (инициирование активности обучающегося) и рефлексия (сравнение, анализ, оценка своей деятельности и ее результатов) $[2 ; 12]$.

В условиях аудиторного обучения И.А. Зимняя характеризует учебное взаимодействие как многоплановое и полиморфное с позиции «преподаватель - обучающийся», «обучающийся - обучающиеся», «преподаватель - группа». При этом каждая из взаимодействующих сторон реализует свою субъектную активность [3]. Эту точку зрения разделяет Н.Е. Щуркова, считающая, что «содержательная ткань учебного взаимодействия» должна включать самые высокие способы и формы современной культуры общения между людьми, а само оно должно строиться на «паритетных основаниях двух субъектов деятельности» [11. С. 14].

Учитывая вышесказанное, для организации эффективного аудиторного учебного взаимодействия необходимо:

- рассматривать личность как его наивысшую ценность (гуманистический подход);

- способствовать активной деятельности обучающегося (деятельностный подход);

- оказывать содействие успеху обучающегося, научить его быть счастливым (феликсологический подход);

- совместно анализировать результаты учебного взаимодействия (рефлексивный подход) [11].

В аудиторном обучении используются различные педагогические технологии: коммуникативные, игровые, технологии развития критического мышления, а также информационные технологии. К наиболее часто используемым в образовательном процессе средствам информационных технологий, направленных на повышение интеллектуальной и творческой составляющей учебной деятельности, можно отнести: электронные учебники и пособия, демонстрируемые с помощью компьютера, мультимедийного проектора и интерактивной доски; электронные энциклопедии и справочники; программы тестирования; образовательные ресурсы интернета; электронные носители с фильмами и иллюстрациями; видео- и аудиотехнику [7].

Однако в настоящее время складываются такие непростые ситуации, когда осуществление аудиторного учебного взаимодействия затрудняется или делается в принципе невозможным. В этом случае встает вопрос о переходе к дистанционному обучению.

Дистанционное учебное взаимодействие понимается нами как интерактивный контакт преподавателя и обучающихся, находящихся на расстоянии.

Для дистанционного учебного взаимодействия характерны все присущие аудиторному взаимодействию компоненты: смысл, цели, содержание, организационные формы, средства обучения, система контроля и оценки результатов.

К особенностям дистанционного учебного взаимодействия можно отнести: 
- гибкость (комфортное место и время для решения педагогических и учебных задач);

- модульность (каждый отдельный курс создает целостное представление об определенной области знаний);

- экономичность (статистика показывает, что дистанционное обучение менее затратно, чем аудиторное);

- специфичность (использование специализированных технологий и форм контроля) [5].

В основе дистанционного обучения источниками знаний являются информационные ресурсы сети (базы данных и информационные системы), телекоммуникации, предоставляющие обучающимся возможность работы не только с преподавателем, но и самостоятельно с учебными материалами, возможность заниматься в группе, а также осуществлять анализ и оценку знаний и умений, полученных в ходе учебного взаимодействия.

В научной литературе (Е.С. Полат) в дистанционном учебном взаимодействии выделяются следующие основные модели:

Модель № 1: интеграиия очных и дистанционных форм обучения.

Дистанционная форма обучения осуществляется здесь с помощью специально созданного сайта и необходима для решения учебных задач в рамках индивидуальных планов (реализация личностно ориентированного подхода), для разгрузки от рутинных видов деятельности очного обучения, для индивидуальных консультаций с преподавателем.

Модель № 2: сетевое обучение.

Эта модель может быть представлена автономным электронным курсом дистанционного обучения или информационно-образовательной средой (например, университет), направлена на решение проблем с расписанием. Часть предметов могут изучаться очно, часть - дистанционно. При этом деятельность преподавателя и деятельность обучающихся осуществляется в удобное для них время, за исключением видеоконференций.

Модель № 3: сетевое обучение и кейс-технологии.

Основная нагрузка закреплена за дистанционным обучением, но на короткий промежуток времени обучающиеся вызываются на семинары и конференции очно.

Модель № 4: видеоконференции, интерактивное телевидение.

Данная модель имитирует очную форму обучения, связана с телевизионными технологиями, обеспечивающими трансляцию занятий с помощью видеокамер и специального оборудования на расстоянии, поэтому является достаточно дорогой [6].

Каждая из представленных выше моделей имеет свою специфику, преследует решение конкретных дидактических целей и задач, имеет своего пользователя.

Таким образом, можно отметить, что, несмотря на ряд существенных отличий (живое и дистанционное общение, разные способы работы с информацией, отличие в месте и временном интервале обучения, разница в формах контроля и оценивания и т. д.), аудиторное взаимодействие и дистанционное учебное взаимодействие обладают и схожими чертами (направленность на активную личность, развитие самостоятельности, использование актуальных педагогических технологий и т. д.), что способствует плавному переходу к дистанционному обучению, обусловленному прежде всего требованиями федерального образовательного стандарта как к будущим специалистам, так и к педагогам, развитием научно-технического прогресса, а также современной обстановкой в мире.

\section{Этапы перехода к дистанционной форме обучения}

Основываясь на теоретических исследованиях учебного взаимодействия, мы выделяем следующие этапы его перехода от аудиторной к дистанционной форме.

Эman 1. Предварительное изучение мнения студентов и преподавателей о дистанционном обучении.

Эman 2. Выявление и обоснование педагогических условий, способствующих эффективному дистанционному учебному взаимодействию.

Этаn 3. Разработка структурированной программы дистанционного учебного взаимодействия.

Изучение мнения студентов и преподавателей

Нами был разработан небольшой опросник для группы студентов-лингвистов первого и второго курсов Института языка и литературы Удмуртского государственного университета, включающий вопросы открытого типа, а также с вариантами ответов, на которые ответило 20 человек. 
На первый вопрос об оценке своих навыков работы с компьютером большинство студентов 17 человек (85\%) - отнесли себя к уверенным пользователям компьютера и сети Интернет, оставшиеся 3 человека (15\%) считают себя просто пользователями. Уверенные пользователи на достаточно высоком уровне разбираются в самом компьютере, способны создать точку восстановления информации, сделать дефрагментацию диска, знают, что такое резервное копирование и архиваторы, могут установить любую необходимую программу. Хотя никто не отнес себя к профессионалам в этой области, на техническом уровне опрошенная группа оказалась очень хорошо подготовлена и, в принципе, открыта для информационного пространства.

На второй вопрос об организации процесса дистанционного обучения в вузе 16 человек $(80$ \%) дали ответ «частично удовлетворен», 4 человека (20\%) оказались полностью удовлетворены, неудовлетворенных не оказалось. Таким образом, можно сделать вывод, что особого дискомфорта, находясь на дистанционном обучении, группа не испытывает.

На третий вопрос все студенты (100\%) в качестве ведущих площадок дистанционного обучения назвали Skype, Zoom, электронные курсы преподавателей в системе электронного обучения вуза, 2 студента (10\%) добавили к этому Viber, социальную сеть «ВКонакте», Adobe Connect, 2 студента (10\%) упомянули электронную почту.

При этом были отмечены преимущества и недостатки Skype и Zoom. Оба приложения хорошо подходят для групповых занятий. По мнению обучающихся, работа в Skype не ограничена по времени, но скорость и качество связи не очень высокие. Zoom имеет временной лимит, но функционирует быстрее и требует меньше оперативной памяти компьютера. Видеосвязь по Viber больше подходит для индивидуальных консультаций. Электронная почта ориентирована на размещение каких-то объявлений и отправления письменных работ.

В ответе на четвертый вопрос о положительных моментах дистанционного обучения почти все опрошенные подчеркивают большее количество свободного времени, достаточно гибкий, зависящий от самого студента график учебы, комфортную домашнюю обстановку - 19 человек (95 \%). Один из студентов (5\%), кроме этого, относит к плюсам минимум обучающих средств: интернет и любой гаджет. Еще 2 студента (10\%) добавляют, что задания, выполненные вне университетской аудитории, более качественны. Ничего положительного в дистанционном обучении не смог найти 1 человек (5\%).

К негативным фактам (пятый вопрос) 16 студентов (80\%) отнесли плохое качество связи и другие технические проблемы, большой объем домашнего задания, а также недостаточное количество практических занятий, на которых можно было бы осуществить общение на иностранном языке. Один студент (5\%) считает, что в дистанционном режиме теряются мотивация и дисциплина, иногда отсутствует возможность обсудить какой-то непонятный вопрос сразу же, как на аудиторном занятии. Еще один (5 \%) сообщает о некомпетентности некоторых преподавателей осуществлять учебный процесс дистанционно с помощью интернет-технологий. Два студента (10\%) пишут о негативном влиянии компьютера на их здоровье: страдают зрение и осанка.

Консультации с преподавателем (шестой вопрос) 18 человек (90 \%) хотели бы проводить очно или по видеосвязи. Двум студентам (10\%) достаточно электронной почты. Очевидно, что обучающимся не хватает живого общения с преподавателем.

И наконец, на последний (седьмой) вопрос о полном переходе на дистанционное обучение 15 человек (75\%) ответили однозначно негативно, 3 человека (15\%) - утвердительно, 2 человека (10 \%) предлагают сочетать аудиторное и дистанционное обучение.

Данные результаты в какой-то степени иллюстрируют отношение обучающихся к дистанционному учебному взаимодействию, однако во многом зависят от субъективных факторов. Например, личностные особенности студента: скромному человеку комфортнее спрятаться за монитором компьютера и отправлять электронные письма преподавателю. Далее, в связи с определенными материальными проблемами качество гаджетов может быть низким и не соответствовать требованию некоторых программ, или они вообще могут отсутствовать. Проживание за городом влияет на качество связи, а, следовательно, какая-то информация при отсутствии интернета может быть упущена.

Некоторые преподаватели с осторожностью относятся к цифровизации учебного процесса, не говоря уже о переходе к дистанционному обучению в принципе. Однако компьютер и все, что с ним связано, - это наше настоящее. Поэтому на уровне многих учебных заведений идет соответствующая подготовка преподавательского состава, налаживается их сотрудничество с программистами. 
На сайте профсоюзных работников Удмуртского государственного университета представлены результаты опроса 169 преподавателей о дистанционном обучении [15].

Интересно проанализировать ответы на некоторые вопросы. Так, 102 опрошенных преподавателя (60\%) в целом оказались готовы к работе в дистанционном формате, и лишь 5 человек (3 \%) не готовы. При этом ранее 132 преподавателями (78 \%) из возможных дистанционных форм взаимодействия со студентами использовалась только электронная почта. К негативным моментам 69 человек (41 \%) отнесли увеличение рабочего времени, уменьшение свободного (в отличие от студентов!), 62 человека (37 \%) сообщают о слабых технических возможностях личной техники, 60 (36 \%) - техники студентов, 56 преподавателей (33 \%) подчеркивают низкую дисциплину студентов. О повышении качества учебного взаимодействия пишут 45 опрошенных (27\%), столько же - о его ухудшении. 71 преподаватель (42 \%) считает, что переход к дистанционному обучению как положительно, так и отрицательно влияет на качество образования. 143 преподавателя $(85 \%)$ осуществляют обратную связь со студентами в форме диалога через социальные сети, электронную почту или Skype. Особенно важным, как нам кажется, является факт, что, несмотря на возникающие сложности, 137 опрошенных преподавателей $(81 \%)$ с оптимизмом смотрят в будущее и считают приобретаемый опыт полезным и необходимым.

\section{Педагогические условия эффективного дистанционного учебного взаимодействия}

Представленный анализ дистанционной образовательной деятельности с позиции преподавателей и обучающихся свидетельствует о том, что учебное взаимодействие пока нельзя назвать абсолютно эффективным. Процесс перехода от аудиторного к дистанционному обучению находится в начальной фазе своего развития, не имеющей четкой структуры и системности.

На наш взгляд, эффективному дистанционному учебному взаимодействию будут способствовать определенные педагогические условия, обеспечивающие личностный и профессиональный рост преподавателя и обучающихся.

1. Педагогическое содействие, рассматриваемое как сотрудничество педагога и студентов, основанное на латентных механизмах управления мыслительной деятельностью обучающихся, а также педагогической пресуппозиции, повышающей самооценку и достоинство личности, укрепляющей социальные отношения.

Это условие обосновывается прежде всего принципами гуманистической парадигмы образования: принципом равенства преподавателя и ученика, предполагающим их совместную деятельность в учебном процессе; принципом диалогизма и свободы, опирающимся на взаимное обогащение и свободу выбора; принципом принятия личности такой, какая она есть (Е.В. Бондаревская, А. Маслоу, Д.И. Фельдштейн, Г.Н. Филонов и др.). А также идеями личностно ориентированного подхода об индивидуальности личности в учебном процессе, ориентированном на ее развитие и совершенствование (С.В. Белова, В.В. Сериков, С.А. Комиссарова, И.С. Якиманская и др.).

2. Технологическое сопровождение, включающее совокупность оптимальных образовательных ресурсов, форм и средств, используемых в дистанционном учебном взаимодействии.

Второе условие базируется на положениях современных ученых, рассматривающих педагогические условия как взаимосвязь возможностей содержания, методов и форм целостного учебного процесса, направленных на достижение поставленных целей и задач, а следовательно, на его эффективность (В.А. Беликов, Е.И. Козырева, С.Н. Павлов, А.В. Сверчков и др.).

Данные условия должны реализоваться в соответствующей программе дистанционного учебного взаимодействия, наделенной следующими функциями:

- коммуникативная (осуществление диалога в разных режимах: обучающийся - компьютер, обучающийся - преподаватель, обучающийся - группа, обучающийся - обучающийся);

- информативная (использование компьютерных информационных ресурсов и ресурсов сети Интернет);

- управляющая (возможность настройки программы на определенный уровень знаний обучающегося, его интересы и возрастные особенности);

- контролирующая (проверка и оценка действий обучающегося) [4. С. 13].

Структурные компоненты программы дистанционного учебного взаимодействия можно изобразить схематично (рис.).

Каждый из представленных блоков попытаемся содержательно наполнить на примере дистанционного учебного взаимодействия студентов-лингвистов первого курса, изучающих немецкий язык как второй иностранный. 


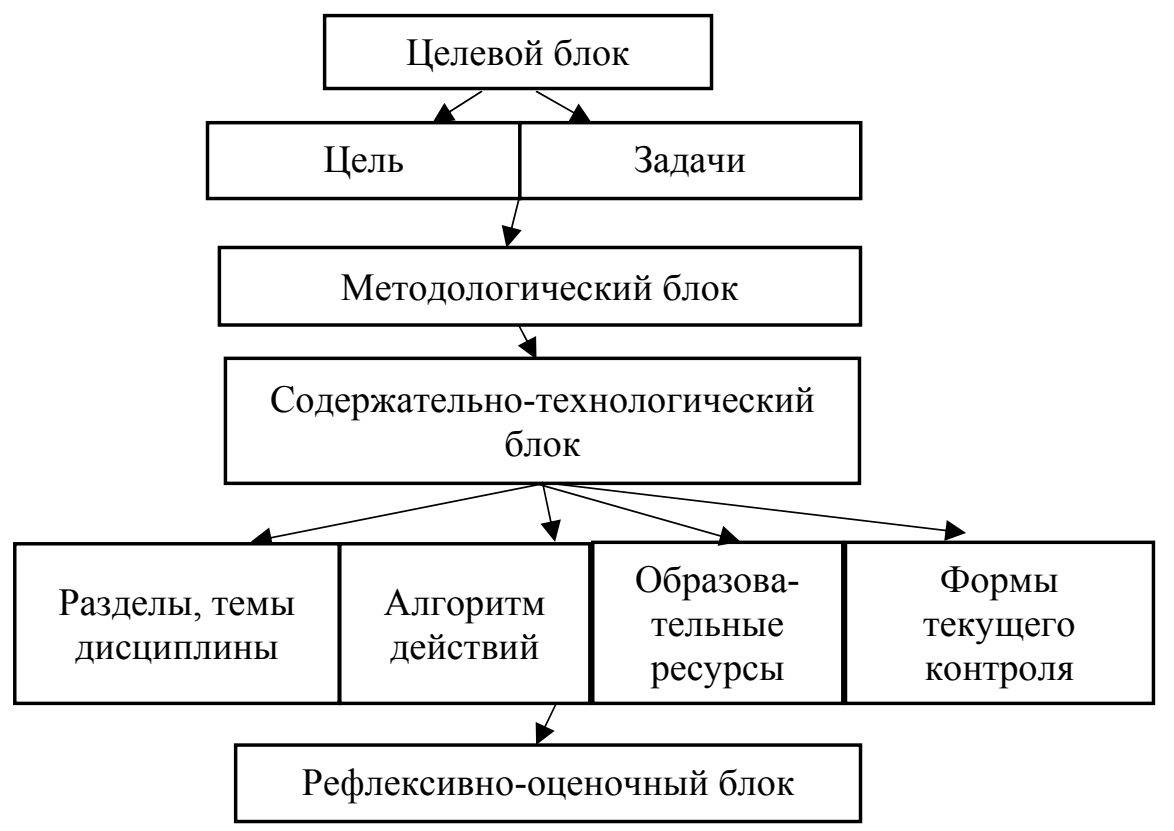

Рис. Программа дистанционного учебного взаимодействия

\section{Целевой блок}

Целью дистанционного учебного взаимодействия является овладение обучающимися суммой общекультурных и профессиональных компетенций (лингвистической, социолингвистической, социокультурной, когнитивно-познавательной, рефлексивно-оценочной, коммуникативно-деятельностной), соответствующих общеевропейскому уровню А1. Для достижения поставленной цели необходимо решение следующих задач: овладение фонетическим и лексико-грамматическим материалом; изучение норм поведения в типичных ситуациях общения; ознакомление с системой ценностей изучаемого языка и культуры; формирование навыков контрастивного анализа языкового материала; формирование навыков организации и оценки собственной учебной деятельности; формирование навыков учебного взаимодействия.

\section{Методологический блок}

Методология исследования дистанционного учебного взаимодействия связана в первую очередь с синергетическим подходом, базирующимся на принципах как взаимодействия, так и самоорганизации (К.И. Князева, С.П. Курдюмов, Н.Я. Сайгушев и др.) и идеями личностно ориентированного подхода (А.С. Белкин, Н.Е. Щуркова, И.С. Якиманская и др.). К теоретическим основам относятся также современные научные положения отечественной и зарубежной науки о социальной сущности взаимодействия и его роли в развитии личности (В.С. Грехнев, Р. Каммингс, М.М. Рыбакова, Ф. Озер и др.); положения рефлексивно-гуманистического подхода (С.Н. Маслов, И.Н. Семенов, В.А. Сластенин и др.); положения об информационных технологиях как отрасли дидактики, занимающейся изучением планомерно и сознательно организованного процесса обучения и усвоения знаний (Е.И. Машбиц, Е.С. Полат, В.Ф. Шолохович и др.).

Содержательно-технологический блок

Дистанционное учебное взаимодействие, как и аудиторное, должно иметь определенный алгоритм действий: введение в тему (раздел), осознание и осмысление нового учебного материала, активизация полученной информации в учебных заданиях и ситуациях, интеграция учебного материала в профессиональную деятельность, контроль качества обучения в рамках данной темы (раздела). Реализации данного алгоритма способствуют оптимально выбранные образовательные ресурсы, а также методы, средства и формы учебного взаимодействия. 


\section{Описание опыта дистанционного обучения по разработанной нами программе}

Рассмотрим выше сказанное на конкретном примере: изучение лексической темы «Квартира» (Die Wohnung).

1. Введение в тему.

Обучающимся предлагается глоссарий, познакомиться с которым они могут в электронном курсе.

«Практический курс немецкого языка как второго иностранного для начинающих» (вторая тема) [13]. Погружение в новую лексику начинается самостоятельно, и взаимодействие происходит пока в режиме «обучающийся - компьютер». На практическом занятии в Skype преподаватель читает (рассказывает) полилог про новую квартиру, используя изученные студентами новые слова и выражения, создавая соответствующую образовательную ситуацию и плавно принимая в нее обучающихся, у которых создается эффект понимания, казалось бы, незнакомого материала.

2. Осознание и осмысление нового учебного материала.

Студенты читают полилог по ролям, осуществляя последовательный перевод каждой реплики.

Взаимодействие в Skype в режиме «обучающийся-обучающийся». Функция преподавателя консультативная. Далее все переходят на другую образовательную площадку - обучающий сайт Schubert-Verlag Online Aufgaben Deutsch als Fremdsprache (уровень A1, глава 11) [14] - и выполняют ряд заданий на заполнение пропусков в тексте новыми словами. Контроль осуществляется с помощью загоревшегося светофора (красный цвет - неверно, зеленый - верно). Оценка осуществляется в процентах. У обучающегося всегда есть шанс самостоятельно добиться правильного варианта, так как красный светофор, не показывая правильного варианта, латентно руководит его мыслительной деятельностью. Если все-таки не получается добиться корректного ответа, можно получить его в рамках справочноинформационной поддержки, нажав на светофор, и проанализировать свои действия.

3. Активизация полученной информаџии в учебных заданиях и ситуациях.

Обучающиеся самостоятельно работают с текстами из электронного курса: читают, переводят, выписывают незнакомые слова, составляют вопросы. На практическом занятии в скайпе происходит презентация неподготовленного диалога по содержанию текстов. На экране появляются два студента, задающие друг другу вопросы и отвечающие на них. Если у слушающих остались незаданные вопросы, они задают их в конце диалога только что говорившим студентам. Для создания благоприятного климата и подобия «живого общения» важен визуальный контакт, поэтому все отвечающие включают камеру. На этом этапе можно поработать с видео. Extra Deutsch - обучающий сериал на немецком языке с интересным сюжетом и смешными жизненными ситуациями. В первой серии «Sams Ankunft» описывается прибытие американца в Берлин, в квартиру его подруги по переписке. Фильм можно смотреть с субтитрами или без них, лучше в индивидуальном режиме. Далее обучающиеся работают в минигруппах, выполняя определенные задания, предлагаемые ими самими. Таким образом, преподаватель латентно инициирует активность студентов, способствует развитию их самостоятельности. Задания могут быть различными: представить и описать действующих лиц, сделать последовательный перевод небольшого отрывка, озвучить отрывок, задать вопросы, касающиеся деталей фильма, и т. д.

4. Интеграция учебного материала в профессиональную деятельность.

Так как профессия переводчика является публичной, он должен владеть определенными качествами: четко и грамотно излагать свои мысли, выступать перед аудиторией. Поэтому на данном этапе учебного взаимодействия можно поработать с powerpoint-презентациями, которые студенты готовят самостоятельно, используя необходимые материалы: интернет-ресурсы, а также учебные пособия, необходимые для освоения данной дисциплины. В рамках заданной темы презентацию можно посвятить обсуждению квартиры (или дома) своей мечты. Обязательным моментом каждой презентации должна быть завуалированная проверка внимания слушающих. Например, перевод некоторых предложений, вопросы на уровне деталей. Такая обратная связь выступающего с группой рассматривается нами как элемент педагогизации учебного взаимодействия.

5. Контроль качества обучения в рамках темы.

Текущий контроль по теме может осуществляться в письменной форме: написание сочинения или эссе. В нашем электронном курсе это описание фотографии с изображением комнаты. Студенту необходимо не просто рассказать, что где находится, но и предположить, кто живет в этом помещении, какие у него характер, профессия. Письменные работы отправляются преподавателю в виде файла на электронную почту. Сочинения разбираются в специально отведенное для индивидуальных 
консультаций время в Skype или Viber, либо некоторые из работ обсуждаются совместно со всеми на практическом занятии. У каждого студента есть возможность выступить в роли преподавателя и попробовать исправить ошибки писавшего. На этом же этапе обучающиеся проходят тестирование в рамках электронного курса, имеющее ограничение во времени и количестве попыток. Задание оценивается по пятибалльной шкале. Заметим, что система оценивания при создании электронных курсов выбирается преподавателем. Пятибалльная шкала - самый простейший способ. Работа обучающегося может быть оценена в процентном соотношении или состоять из суммы баллов за каждое сделанное задание. В качестве обратной связи могут быть использованы соответствующие смайлы или высказывания типа «Отлично! Молодец!», «Ответ неверен, прочитайте теорию по этому вопросу, и все получится» и т. д., создающие ситуацию успеха.

Таким образом, содержательно-технологический блок работы над темой «Квартира» реализуется путем использования таких образовательных ресурсов, как электронный учебный курс, обучающий сайт в сети Интернет, обучающее видео, электронные и бумажные учебные пособия. В рамках этих ресурсов используются методы, открытые для решения педагогической задачи: ролевая игра, позиционная дискуссия, метод проектов, исследовательский метод. Важно, что все четыре вида речевой деятельности (аудирование, говорение, чтение, письмо) здесь задействованы. Дистанционное учебное взаимодействие осуществляется на электронных площадках Skype (или реже - Viber, электронная почта) с использованием всех форм взаимодействия: «обучающийся-преподаватель», «обучающийся компьютер», «обучающийся - группа», «обучающийся - обучающийся», «преподаватель - группа».

\section{Рефлексивно-оценочный блок}

Рефлексия в учебном взаимодействии является первостепенным условием для оптимизации развития и саморазвития всех участников данного процесса, способствует формированию самостоятельности как активной мыслительной деятельности обучающихся. Информация, добытая путем преодоления некоторых объективных трудностей, по мнению специалистов, усваивается прочнее, так как человек не может оставаться безучастным и пассивным [8; 9].

Сущность данного блока заключается в анализе и осмыслении полученной информации и практического опыта: что получилось? где возникли трудности? почему? что нового я узнал? что было особенно полезно? Ответы на данные вопросы лучше разбирать с преподавателем. Тогда можно будет говорить о совместной рефлексии учебного взаимодействия.

Предварительные выводы об учебном взаимодействии в рамках дистанционного обучения

В результате теоретического и практического изучения данного вопроса под дистанционным учебным взаимодействием мы будем понимать контакт удаленных друг от друга преподавателя и обучающихся, основывающийся на принципе самостоятельности, взаиморегулировании, осуществляемый посредством механизмов личностного и социального самопреобразования и ведущий к интеллектуально-творческому росту обеих сторон.

Безусловно, такой вид взаимодействия имеет свои преимущества и недостатки.

К положительным моментам в дистанционном учебном взаимодействии можно отнести в первую очередь богатство учебных и контролирующих материалов сети Интернет, которые всегда под рукой, которые можно быстро обновить, изменить в рамках сложившейся образовательной ситуации. Достаточно просто ввести ключевое слово, чтобы найти нужный текст, фактические данные, техническую информацию, фотографии или фильмы. На аудиторном занятии интернет-соединение часто отсутствует, не в каждом помещении есть компьютеры. Дистанционное обучение создает условия для осуществления обучающих, учебных и контролирующих действий в режиме комфортного места и времени. Плюсом является также компьютерное тестирование, сокращающее время проверки материала, освобождающее от трудоемкой обработки результатов, обладающее максимальной объективностью.

Особые проблемы в дистанционном взаимодействии педагога и обучающихся, на наш взгляд, возникают при создании ситуации успеха, оценивании ошибок и совместной рефлексии учебного процесса. На расстоянии, часто не имея возможности видеть, а только слышать студентов, или просто, читая выполненные дома работы, трудно латентно руководить их мыслительной деятельностью, сразу же реагировать на их ошибки и промахи, регулировать взаимодействие внутри группы. Также дистанционное обучение более энергозатратно для преподавателя, так как он вынужден постоянно координировать группу в онлайн-режиме (все ли слышат его, друг друга, все ли получили и поняли задание и т. д.), проверять большее по объему количество письменных работ (сочинений, эссе и т. д.), 
выполненных в рамках электронного курса. Кроме того, при осуществлении контроля возникает вопрос о том, насколько самостоятельно было сделано задание. Исключением является видеосвязь, являющаяся обязательной при сдаче текстов и диалогов наизусть.

\section{Методические рекомендации}

Исходя из проанализированного теоретического и практического материала, базируясь на положениях синергетического, личностно-ориентированного и рефлексивно-гуманистического подходов, можно предложить некоторые общие методические рекомендации, целью которых является оказание помощи преподавателям в организации эффективного дистанционного учебного взаимодействия:

- Отключайте и убирайте все ненужные гаджеты, закрывайте окна социальных сетей. Призывайте сделать то же самое своих студентов. Это поможет максимально сосредоточиться на учебном взаимодействии, направит деятельность всех его участников в нужное русло познания.

- Заранее проверяйте техническое оборудование, чтобы процесс учебного взаимодействия носил непрерывный, целостный и системный характер.

- По возможности используйте видеосвязь с компьютера, а не с телефона. Рекомендуйте это же обучающимся. Экран монитора компьютера гораздо больше, чем экран телефона, позволяет открыть несколько вкладок одновременно. Условия восприятия и обработки информации становятся более благоприятными, что, в сою очередь, способствует быстрой активизации знаний.

- Задавайте периодически вопросы о качестве связи. Смотрите на сообщения в чате. Проводя занятие онлайн, вы находитесь по другую сторону монитора и не всегда можете контролировать деятельность студентов. Возможно, у кого-то возникли проблемы с микрофоном или камерой, а учебное взаимодействие предполагает активность всех и каждого.

- Старайтесь использовать электронную образовательную площадку исходя из целей взаимодействия и количества его участников. Некоторые обучающие программы не выдерживают большого количества обучающихся, и учебный процесс способен прерваться в самый неподходящий момент, что нарушает уже сложившуюся рабочую атмосферу, негативно сказывается на эффективности учебного взаимодействия.

- Используйте разные методы и формы работы с информацией. Каждый метод определяется конкретной образовательной ситуацией, имеет разный уровень сложности, преследует определенную цель: формирование системного мышления, создание личностно значимой мотивации, развитие способности работать в группе, развитие самостоятельности и т. д.

- Анализируйте и оценивайте результаты своей деятельности. Делайте это вместе со студентами. Это поможет совершенствовать процесс учебного взаимодействия, анализировать его на уровне деталей и целостно, научить обучающихся делать самостоятельные выводы.

\section{Заключение}

В статье сделана попытка изучить особенности дистанционного учебного взаимодействия, выявить педагогические условия его эффективности, реализующиеся в соответствующей программе на примере студентов-лингвистов, проанализировать мнение преподавателей и обучающихся о новом формате образовательной деятельности. Работа открывает ряд перспектив на изучение значимых характеристик дистанционного учебного взаимодействия на стыке многих наук: педагогики, дидактики, психологии, лингвистики, а также информатики и программирования; на разработку соответствующих профессионально ориентированных технологий.

Дистанционное обучение в современных условиях, а также в режиме определенных ограничений, в том числе и ограничений возможности посещать места работы и учебы, становясь вынужденной необходимостью, может быть направлено в оптимальное для всех русло, это одна из важнейших задач нашего образования.

\section{СПИСОК ЛИТЕРАТУРЫ}

1. Афонин И.Д. Психология и педагогика высшей школы. М.: Русайнс, 2018. 256 с.

2. Брим Н.Е. Формирование умений учебного взаимодействия у студентов в образовательной деятельности: автореф. дис. ... канд. пед. наук: 13.00.01. Ижевск, 2007. 19 с.

3. Зимняя И.А. Педагогическая психология. Ростов-н/Д: Феникс, 1997. 480 с. 
4. Зубов А.В., Зубова И.И. Методика применения информационных технологий в обучении иностранным языкам: учеб. пособие для студ. высш. учеб. заведений. М.: Изд. центр «Академия», 2009. 144 с.

5. Нестерова С.А. Организация дистанционного обучения с помощью современных ИКТ: метод. рекомендации для педагогов образов. учреждений. Новокуйбышевск, 2009. 32 с.

6. Полат Е.С. Дистанционное обучение в профильных классах общеобразовательной школы // Информатика и образование. 2007. № 3. С. 10-17.

7. Потапова Р.К. Новые информационные технологии и лингвистика. М.: КомКнига. 2005. 368 с.

8. Реан А.А. Рефлексивно-перцептивный анализ в деятельности педагогов. // Вопросы психологии. 1990. № 2. C. 77-81.

9. Сайгушев Н.Я. Сущностно-содержательная модель рефлексивного управления профессиональным становлением будущего учителя. Спб., 2001. 148 с.

10. Сластенин В.А., Исаев И.Ф., Мищенко А.И., Шиянов Е.Н. Педагогика: учеб. пособие. М.: Шк. пресса. 2004. $512 \mathrm{c}$.

11. Щуркова Н.Е. Педагогическая технология. М.: Педагогическое общество России. 2002. 224 с.

12. Oser F. Eine basale pädagogische Handlungsstruktur. München. 1994. S. 773-800.

13. Курс «Немецкий язык как второй иностранный для начинающих» [Электронный ресурc]. URL: https://distedu.ru/course/view.php?id=667 (дата обращения: 30.05.2020).

14. Обучающий сайт по немецкому языку [Электронный ресурc]. URL: https://www.schubert-verlag.de/aufgaben/ index.htm, свободный (дата обращения: 30.05.2020).

15. Результаты опроса преподавателей УдГУ о переходе на дистанционное образование [Электронный ресурс]. URL: $\quad$ https://profcom.udsu.ru/news/show/rezultaty-oprosa-prepodavatelej-udgu-o-perehode-na-distantsionnoeobrazovanie (дата обращения: 30.05.2020).

Поступила в редакцию 01.06.2020

Брим Наталья Евгеньевна, кандидат педагогических наук, доцент кафедры романской филологии второго иностранного языка и лингводидактики Института языка и литературы

ФБГОУ ВО «Удмуртский государственный университет»

426034, Россия, г. Ижевск, ул. Университетская, 1

E-mail: brim75@mail.ru

\section{N.E. Brim \\ ACADEMIC INTERACTION IN DISTANCE LEARNING (ON THE EXAMPLE OF STUDENTS-LINGUISTS)}

DOI: $10.35634 / 2412-9550-2020-30-3-313-322$

The article deals with the problem of organizing distance learning academic interaction based on the provisions of a synergistic and personality-oriented approach to the educational interaction of teachers and students as a self-organizing and mutually enriching system. The effectiveness of this interaction is achieved by identifying and substantiating the relevant pedagogical conditions: pedagogical assistance and technical support, implemented in the structural components of the distance learning interaction program. The article describes the models of distance learning interaction and the algorithm of actions of its participants, draws attention to the selection of optimal educational resources: methods, forms and means of distance learning. The article also presents and analyzes the results of a survey of teachers of Udmurt State University and students-linguists studying a foreign language about the problem of distance learning; some facts from personal experience in this direction are presented. In conclusion, methodological recommendations in the organization of distance learning interaction are given.

Keywords: academic interaction, information and communication technologies, electronic educational environment, distance learning, program.

Brim N.E., Candidate of Pedagogy, Associate Professor at Department of Romance Philology,

Second Foreign Language and Linguodidactics at the Institute of Language and Literature

Udmurt State University

Universitetskaya st., 1, Izhevsk, Russia, 426034

E-mail: brim75@mail.ru 